\section{Isozymes and Canonical Discriminant Analysis to Identify Pistachio (Pistacia vera L.) Germplasm}

\author{
Ettore Barone, Luigi Di Marco, and Francesco P. Marra \\ Istituto di Coltivazioni Arboree, Università di Palermo, 90128 Palermo, Italy \\ Maria Sidari \\ Dipartimento di Agrochimica e Agrobiologia, Università di Reggio Calabria, \\ 89061 Gallina (RC), Italy
}

\section{Additional index words. cultivar, polyacrylamide gel electrophoresis, multivariate analysis}

\begin{abstract}
Canonical discriminant analysis (CDA) of morphometric data of buds, leaves, and fruit, as well as isozyme analysis (esterase, peroxydase, and acid phosphatase) of leaf samples, were used to identify eight male pistachio selections and $\mathbf{1 0}$ female pistachio cultivars. According to the CDA, $77 \%$ and $93 \%$ of the total variance was summarized by the first three canonical discriminant functions for the female and male selections, respectively. Fruit characteristics, particularly fruit fresh and dry weights and fruit length, accounted for most of the discriminatory power for the female cultivars, while the dimensions of the leaves, principally leaf rachis length, were the most effective discriminating characters for the males. Isozyme analysis showed a higher degree of polymorphism in the male than the female genetic pool. Hence, using only three enzymes, it was possible to identify all of the male selections, but only $50 \%$ of the females. Peroxidase polymorphism clearly demonstrated the greater phylogenetic distance between 'Kerman' and the local cultivars, as well as between 'Cerasola', a quite different cultivar with a reddish hull, and the others tested. The combination of CDA and isozyme analysis enhanced the possibility of uniquely identifying the female cultivars.
\end{abstract}

The pistachio tree, native to western Asia and Asia Minor, was introduced into Italy from Syria in A.D. 30 by the Romans (Minà Palumbo, 1882). Its cultivation spread to Sicily during the Arab domination (A.D. 827 to 1040). Despite the long cultivation period, only a few cultivars of pistachio are grown in Sicily, where the Italian industry is located. 'Bianca' is the main cultivar, with others representing $<3 \%$ of the cultivated area (Barone et al., 1985). Most of these minor cultivars are no longer grown commercially nor are they available in nurseries. Therefore, the genetic reserve is being rapidly eroded. Nevertheless, the Sicilian germplasm has some desirable characteristics, such as color, flavor, and nut quality (Caruso et al., 1986, 1987). Indeed, Sicilian pistachios have long been appreciated for the intense green of their kernels and rich, oily nutlike flavor (Woodroof, 1967).

As a part of a breeding research program carried out at the Univ. of Palermo, a germplasm collection was established in 1984, including 'Bianca' and 'Kerman' as standard cultivars, together with eight indigenous cultivars and eight unnamed male pistachio selections. As the possibility of synonymy in such a collection could not be excluded, the varietal identi-

Received for publication 31 Oct. 1995. Accepted for publication 23 Sept. 1995. We are indebted to Giovanni Cacco and Tiziano Caruso of the Univ. of Reggio Calabria for their support and suggestions. The cost of publishing this paper was defrayed in part by the payment of page charges. Under postal regulations, this paper therefore must be hereby marked advertisement solely to indicate this fact. fication of this plant material was recognized as a problem of primary importance.

In the last decade, isozyme techniques have been used to identify cultivars (Torres, 1983). However, few attempts with pistachio are reported (Arulsekar and Parfitt, 1986). Loukas and Pontikis (1979) used pollen isozymes to detect the degree of phylogenetic relationship among various species and types of Pistacia, but, because they were working with pollen, they were limited to studying male genotypes. More recently, Dollo(1991), using leaf samples from 22 species and cultivars of Pistacia grown

Table 1. Standardized canonical coefficient (SCC) and correlation coefficient $(r)$ between the first three canonical discriminant functions $\left(\mathrm{CDF}_{1}, \mathrm{CDF}_{2}, \mathrm{CDF}_{3}\right)$ and variables of the morphometric characters of the female cultivars.

\begin{tabular}{|c|c|c|c|c|c|c|}
\hline \multirow[b]{3}{*}{ Character } & \multicolumn{6}{|c|}{ Canonical discriminant function } \\
\hline & \multicolumn{2}{|c|}{$\mathrm{CDF}_{1}$} & \multicolumn{2}{|c|}{$\mathrm{CDF}_{2}$} & \multicolumn{2}{|c|}{$\mathrm{CDF}_{3}$} \\
\hline & SCC & $r$ & $\mathrm{SCC}$ & $r$ & SCC & $r$ \\
\hline Leaf rachis length & -0.057 & -0.001 & 0.239 & 0.259 & -0.479 & -0.316 \\
\hline Basal leaflet length & 0.361 & 0.225 & 0.090 & 0.346 & 0.360 & 0.180 \\
\hline Basal leaflet width & -0.069 & 0.199 & 0.437 & 0.450 & 0.061 & -0.048 \\
\hline Central leaflet length & -0.313 & 0.142 & -0.440 & 0.216 & 0.431 & 0.119 \\
\hline Central leaflet width & 0.085 & 0.182 & 0.159 & 0.444 & 0.155 & -0.104 \\
\hline Apical leaflet length & 0.248 & 0.228 & -0.182 & 0.189 & 0.035 & 0.065 \\
\hline Apical leaflet width & -0.050 & 0.121 & 0.397 & 0.415 & -0.866 & -0.277 \\
\hline Inflorescence bud length & 0.315 & 0.414 & 0.193 & 0.233 & 0.359 & 0.413 \\
\hline Inflorescence bud max diameter & 0.020 & 0.311 & -0.061 & 0.122 & 0.343 & 0.389 \\
\hline Inflorescence bud min diameter & 0.157 & 0.340 & 0.259 & 0.213 & -0.225 & 0.179 \\
\hline Inflorescence bud fresh weight & 0.037 & 0.367 & -0.061 & 0.194 & -0.112 & 0.282 \\
\hline Inflorescence bud dry weight & 0.331 & 0.379 & 0.212 & 0.188 & 0.237 & 0.297 \\
\hline Fruit length & -0.446 & -0.048 & 0.756 & 0.397 & 0.178 & 0.106 \\
\hline Fruit maximum diameter & 0.312 & 0.473 & -0.031 & -0.138 & -0.275 & -0.322 \\
\hline Fruit minimum diameter & 0.422 & 0.503 & 0.260 & 0.054 & -0.362 & -0.297 \\
\hline Fruit fresh weight & 0.737 & 0.421 & -1.053 & -0.189 & -0.166 & -0.106 \\
\hline Fruit dry weight & -0.597 & 0.186 & 0.396 & -0.145 & 0.417 & -0.010 \\
\hline Variance explained (\%) & \multicolumn{2}{|c|}{43.85} & \multicolumn{2}{|c|}{23.43} & \multicolumn{2}{|c|}{9.62} \\
\hline
\end{tabular}

in Sicily, found some cases of homonymy within those accessions.

A promising method for cultivar identification and classification is offered by the numerical taxonomic approach (Rhodes et al., 1971). Some techniques of multivariate analyses have been applied widely to discriminate and classify cultivars and clones of several fruit tree species (Alessandri and Casini, 1992; Cruz-Castillo et al., 1992; Gogorcena and Ortiz, 1993; Hillig and Iezzoni, 1988; PerezGonzales, 1992), but no report for pistachio was found.

The objectives of this study were to assess the usefulness of a multivariate statistical technique, i.e., canonical discriminant analysis (CDA), and isozyme polymorphism for identifying pistachio cultivars and to determine if synonymy exists in our collection. We also wanted to detect the degree of similarity or dissimilarity within the Italian pistachio germplasm.

\section{Materials and Methods}

Plant material. Two well-known female cultivars, 'Bianca' (A) and 'Kerman' (J), together with eight other putative distinct female cultivars, i.e., 'Cappuccia' (B), 'Cerasola' (C), 'Ghiandalora' (D), 'Gialla' (E), 'Insolia' (F), 'Pignatone' (G), 'Silvana' (H), and 'Tardiva' (I), and eight unnamed male pistachio selections, grown in a germplasm collection at Campobello di Licata (Italy $37^{\circ} 30^{\prime} \mathrm{N}$ ), were examined. The collection was established in 1984 in a randomized block design with 15 trees per cultivar and three trees per male selection. All trees were budded on $P$. terebinthus seedling rootstocks and trained to a vase shape. The main morphological and phenological characteristics of this germplasm have been described by Caruso et al. (1995).

Isozymes. Fully expanded leaves from the median part of nonbearing shoots of 9-year-old trees of each female and male selection were sampled in July and stored at $-20 \mathrm{C}$ up to 1 week. A 0.5-g sample of freeze-dried leaves 
was used. The extraction buffer $(2 \mathrm{ml})$ contained $50 \mathrm{~mm}$ TRIZMA base, an antioxidant (Sigma A1179), $10 \mathrm{~mm} \mathrm{MgCl}_{2}, 10 \mathrm{~mm}$ diethyldithiocarbamic acid, $1 \mathrm{~mm}$ 2mercaptoethanol, and $1.0 \%$ polyethylene gly$\operatorname{col}\left(M_{\mathrm{r}} 3500\right)$. The $\mathrm{pH}$ was adjusted to 8.0 with $0.1 \mathrm{~N} \mathrm{HCl}$. Samples were homogenized in an Ultra-Turrax (Janke and Kunkel, Staufen, Germany) homogenizer for $30 \mathrm{sec}$ with polyvinylpolypyrrolidone and centrifuged for $15 \min (18,100 \times g)$ at $4 \mathrm{C}$; supernatant was collected and centrifuged again. The following extract was immediately used for electrophoresis. Amount of total proteins was measured according to Bradford (1976). A total of $25 \mu \mathrm{l} / \mathrm{sample}$ of extract was submitted to electrophoresis in $12 \%$ polyacrylamide gel for $2.30 \mathrm{~h}$ at constant voltage of $120 \mathrm{~V}, 20 \mathrm{~mA}$, at 4C. The gel electrophoresis apparatus used was the Mini Protean II (Bio-rad, Hercules, Calif.). The enzyme systems studied were esterase (EST), peroxidase (PER), and acid phosphatase (AcPH). Staining procedures were as described by Shaw (1970). The entire procedure was conducted three times.

The results from isozyme analysis were used for producing two matrices of dissimilarity between accessions. Based on these matrices, the grouping of the accessions was made by hierarchical cluster analyses by using normalized percent disagreement as the distance index and the complete linkage method, which uses the most distant pair of objects, to compute between-cluster distances (farthest neighbor). The hierarchy of clusters formed during cluster analysis was illustrated as a dendrogram.

Multivariate analysis. Seventeen variables for each of the 10 females and 12 variables for each of the eight male accessions were determined by at least 50 measurements for each character (Tables 1 and 2), on samples randomly collected from the entire collection. CDA was performed separately on the female and male set of the morphometric data using the MGLH procedure of the SYSTAT statistical package (Wilkinson, 1990). The discriminant power of the obtained canonical discriminant functions was tested by checking predicted vs. actual group membership of each observation, i.e., by applying the obtained canonical discriminant functions (CDFs) to the set of data and calculating the percentage of cases correctly classified. Canonical scores of major CDFs were submitted to analysis of variance (ANOVA). Means of standardized canonical scores of the major CDFs were plotted.

\section{Results and Discussion}

Isozymes. All the enzymes tested were polymorphic. Isozymes of PER were slightly polymorphic, showing three banding patterns for all female cultivars (Fig. 1) and five for male selections (Fig. 2)

Esterases. All the male and the female selections can be divided into five groups, each with identical electrophoretic patterns. Three male selections (M3, M7, and M9) and three female cultivars ('Bianca', 'Cappuccia',
Table 2. Means of standardized canonical scores of the first three canonical discriminant functions (CDF) for the female cultivars.

\begin{tabular}{lccc}
\hline \hline & \multicolumn{3}{c}{ Canonical discriminant function } \\
\cline { 2 - 4 } Cultivar & $\mathrm{CDF}_{1}{ }^{\mathrm{z}}$ & $\mathrm{CDF}_{2}{ }^{\mathrm{z}}$ & $\mathrm{CDF}_{3}{ }^{\mathrm{z}}$ \\
\hline $\mathrm{A}^{\mathrm{y}}$ & $-0.324 \mathrm{c}$ & $0.515 \mathrm{de}$ & $-1.021 \mathrm{ab}$ \\
$\mathrm{B}$ & $0.795 \mathrm{~d}$ & $0.083 \mathrm{~cd}$ & $1.504 \mathrm{e}$ \\
$\mathrm{C}$ & $-0.304 \mathrm{c}$ & $2.524 \mathrm{f}$ & $-0.355 \mathrm{bc}$ \\
$\mathrm{D}$ & $-0.803 \mathrm{c}$ & $1.027 \mathrm{e}$ & $0.716 \mathrm{~d}$ \\
$\mathrm{E}$ & $-0.528 \mathrm{c}$ & $1.021 \mathrm{e}$ & $-0.979 \mathrm{ab}$ \\
$\mathrm{F}$ & $-2.034 \mathrm{~b}$ & $-0.283 \mathrm{c}$ & $-0.401 \mathrm{ab}$ \\
$\mathrm{G}$ & $-0.431 \mathrm{c}$ & $-0.102 \mathrm{~cd}$ & $-0.341 \mathrm{bc}$ \\
$\mathrm{H}$ & $4.651 \mathrm{f}$ & $-1.889 \mathrm{~b}$ & $-1.077 \mathrm{a}$ \\
$\mathrm{I}$ & $2.111 \mathrm{e}$ & $0.224 \mathrm{~cd}$ & $1.693 \mathrm{e}$ \\
$\mathrm{J}$ & $-3.185 \mathrm{a}$ & $-3.187 \mathrm{a}$ & $0.316 \mathrm{~cd}$
\end{tabular}

${ }^{2}$ Mean separation within each column by Tukey's HSD test $(P \leq 0.01)$.

' $\mathrm{A}=$ 'Bianca'; $\mathrm{B}=$ 'Cappuccia'; $\mathrm{C}=$ 'Cerasola'; $\mathrm{D}=$ 'Ghiandalora'; $\mathrm{E}=$ 'Gialla'; $\mathrm{F}$ = 'Insolia'; $\mathrm{G}=$ 'Pignatone'; $\mathrm{H}=$ 'Silvana'; $\mathrm{I}=$ 'Tardiva'; $\mathrm{J}=$ 'Kerman'.

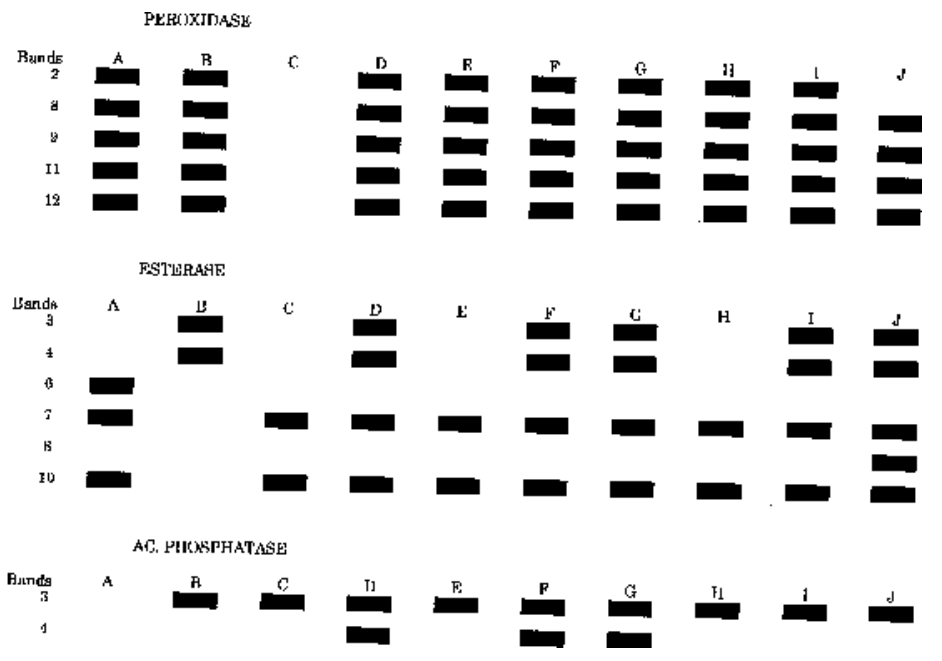

Fig. 1. Schematic zymograms of peroxidase, esterase, and acid phosphatase isozymes in female pistachio cultivars: $\mathrm{A}=$ 'Bianca'; $\mathrm{B}=$ 'Cappuccia'; $\mathrm{C}=$ 'Cerasola'; $\mathrm{D}=$ 'Ghiandalora'; $\mathrm{E}=$ 'Gialla'; $\mathrm{F}=$ 'Insolia'; $\mathrm{G}=$ 'Pignatone'; $\mathrm{H}=$ 'Silvana'; $\mathrm{I}=$ 'Tardiva'; $\mathrm{J}=$ 'Kerman'.
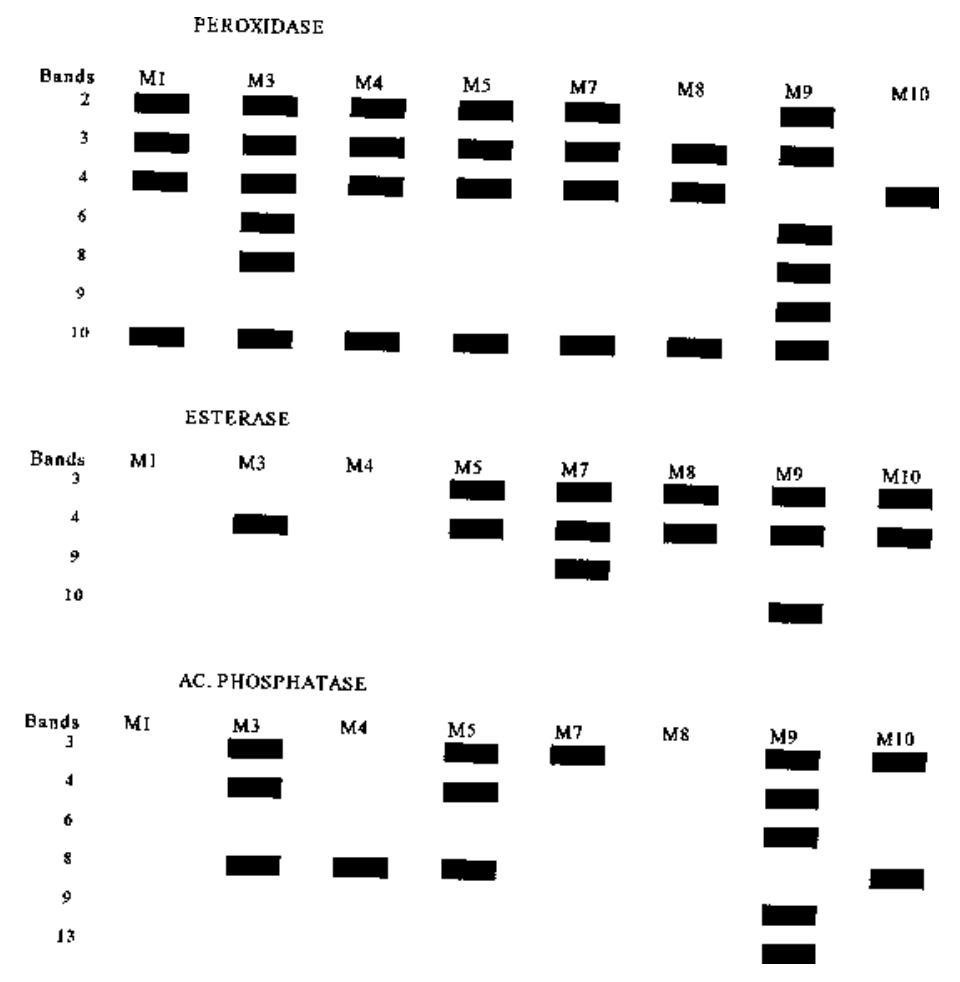

Fig. 2. Schematic zymograms of peroxidase, esterase, and acid phosphatase isozymes in male pistachio selections. 
and 'Kerman') were uniquely identified with this enzyme system.

Peroxidases. Three female and five male groups of selections were evident. This system permitted full discrimination for 'Cerasola' and 'Kerman'. Among the males, differing patterns were shown by selections M3, M8, M9, and M10.

Acidphosphatases. AcPh distinguished six uniform groups of male selections and only three groups of female cultivars. With this system only 'Bianca' could be discerned among the females. Male selections M4, M7, M9, and M10 were uniquely identified.

Using these three enzyme systems together, it was possible to identify all eight male selections, but only these five of the 10 female cultivars: 'Bianca', 'Cappuccia', 'Cerasola', 'Kerman', and 'Tardiva', thus indicating a more pronounced degree of polymorphism among the male than among the female genotypes. Hence, a relative degree of similarity among the Sicilian pistillate cultivars is likely, as evidence from the dendrogram of the studied accessions, based on the results of cluster analysis, demonstrate (Fig. 3).

On the basis of these results, 'Cerasola' and 'Kerman' proved to be fairly distant from the other female cultivars, and M9 from the male selections. This result was expected, considering their extremely different origin and appearance. In contrast, a lower phylogenetic distance can be inferred between 'Gialla' and 'Silvana' and among 'Insolia', 'Pignatone', and 'Ghiandalora'.

Multivariate analysis. Canonical discriminant analysis for the female cultivars showed that a satisfactory degree $(77 \%)$ of the total variance was summarized by the first three canonical functions; i.e., $44 \%, 23 \%$, and $10 \%$, respectively (Table 1 ). All CDFs resulted in significance at $P \leq 0.01$ by the likelihood test. As $\mathrm{CDF}_{4}$ to $\mathrm{CDF}_{9}$ accounted only for $23 \%$ of between-cultivar variation, its contribution was considered negligible; thus, only the first three $\mathrm{CDF}$ s were further examined. Fruit fresh weight, fruit dry weight, and fruit length had the greatest discriminatory power in the first two canonical functions, while apical leaflet width and leaf rachis length (RALE) loaded more on the third function. Nevertheless, the correlation coefficients obtained did not allow us to discern clearly the relative contribution of each character on CDFs (Table 1).

With these three functions, it was possible to clearly separate 'Kerman' and 'Silvana' from the others, since they are located at the opposite extremes of function 1 (Fig. 4A). Furthermore, ANOVA of canonical scores confirmed this clear discrimination (Table 2). 'Pignatone', 'Insolia', and 'Gialla' form a compact group closely surrounding 'Bianca'. Separated from this group are 'Cerasola', mainly for the second function; 'Tardiva' and 'Cappuccia', both for the first function and the third one; and, partially, 'Ghiandalora', for the third function.

About $93 \%$ of the total variance in the male selections was summarized with the first three canonical functions; i.e., $59 \%, 21 \%$, and $13 \%$, respectively (Table 3). All CDFs resulted in
A

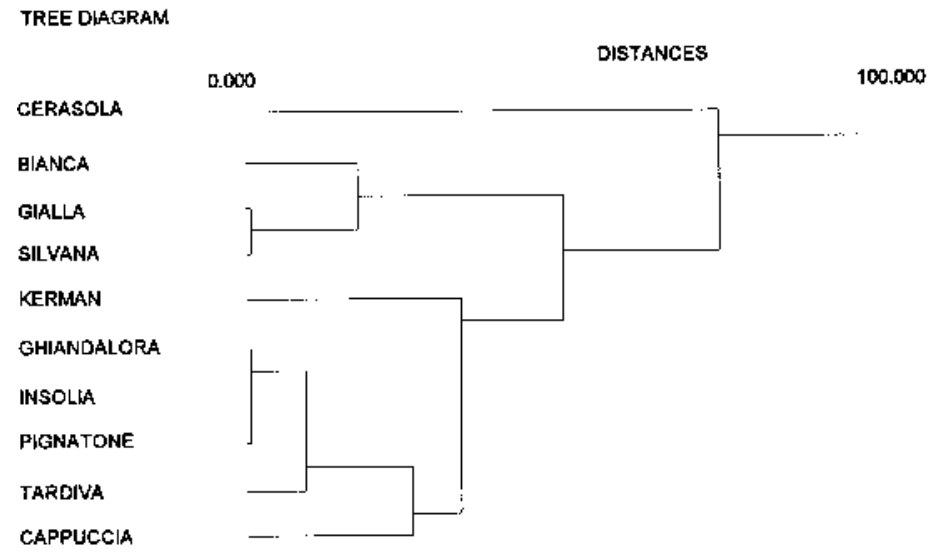

B

TREE DIAGRAM

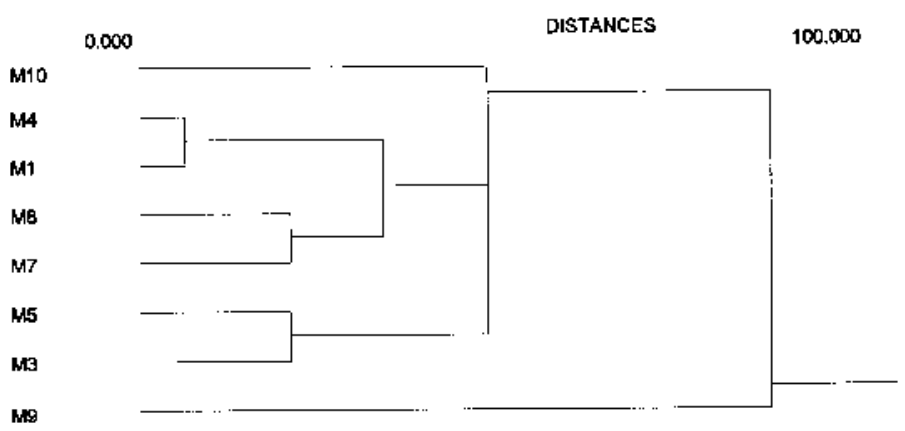

Fig. 3. Dendrogram of the studied accessions based on isozyme analyses. Metric distance calculated by cluster analysis is normalized percent disagreement (complete linkage method—farthest neighbor).

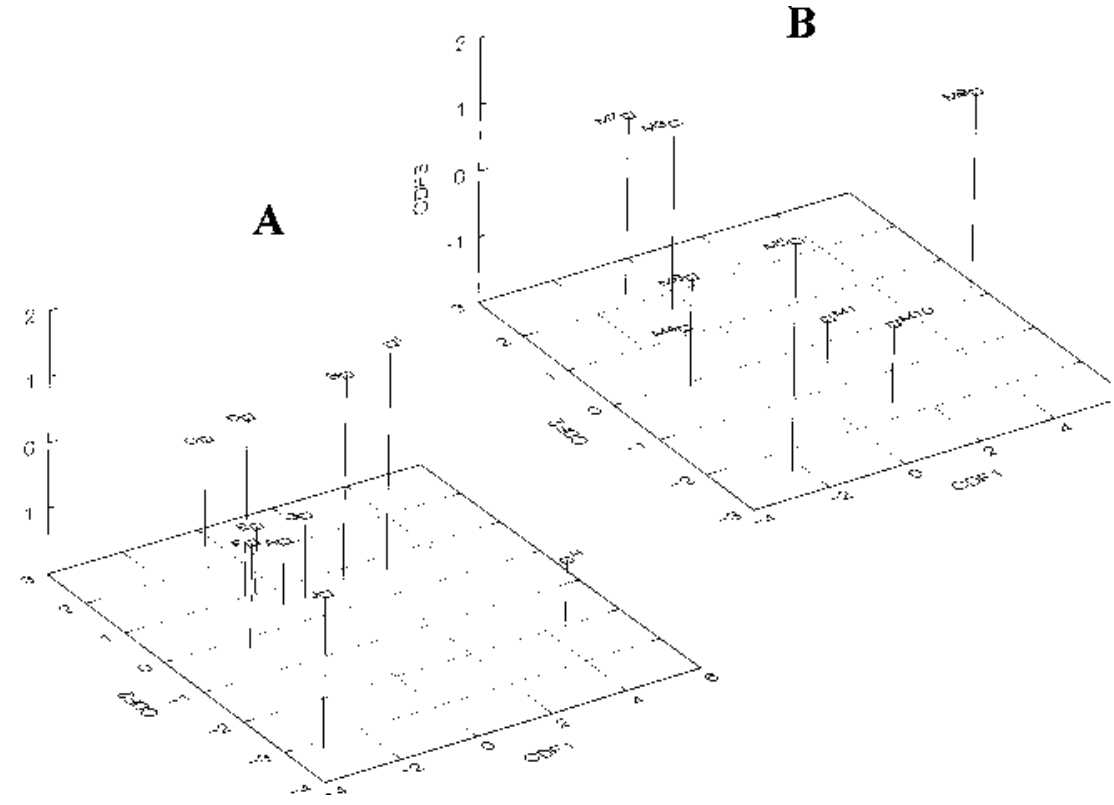

Fig. 4. (A) Means of standardized canonical scores of the first three canonical discriminant functions (CDF) for 10 female pistachio cultivars: $\mathrm{A}=$ 'Bianca'; $\mathrm{B}=$ 'Cappuccia'; $\mathrm{C}=$ 'Cerasola'; $\mathrm{D}=$ 'Ghiandalora'; $\mathrm{E}=$ 'Gialla'; F = 'Insolia'; G = 'Pignatone'; H = 'Silvana'; I = 'Tardiva'; $\mathrm{J}=$ 'Kerman'. (B) Means of standardized canonical scores of the first three CDFs for eight male pistachio selections. 
significance at $P \leq 0.01$ by the likelihood test, except for $\mathrm{CDF}_{7}$. The dimensions of the leaves, above all RALE, were the most separating characters. Particularly, from negative to positive values of function 1, RALE tended to increase; basal leaflet width and the dimensions of inflorescence bud loaded more on $\mathrm{CDF}_{2}$; inflorescence bud fresh weight and central leaflet width loaded more on $\mathrm{CDF}_{3}$. The male selection M9 was clearly separated by the plot of the three CDFs (Fig. 4B, Table 4), while the remaining selections present a scattered distribution, particularly along the axis corresponding to $\mathrm{CDF}_{2}$. Thus, almost all of these selections may be considered to be fairly distinct from one another.

The discriminant power of the canonical functions obtained, as tested by checking predicted vs. actual group membership, was $>70 \%$ in almost all the accessions and particularly high $(>90 \%)$ for some female ('Kerman', 'Silvana', and 'Tardiva') and male (M5, M8, and M9) selections (Table 5). Such values can be considered satisfactory, since values of only $50 \%$ have been considered effective for discriminating between cultivars (Alessandri and Casini, 1992; Ueda and Okada, 1994). Our results are consistent with those of isozyme analysis for 'Kerman', 'Cerasola', and 'Tardiva', which produced distinct patterns. 'Ghiandalora', 'Insolia', and 'Pignatone' formed a compact group. Furthermore, CDA allowed us to discriminate between 'Gialla' and 'Silvana', which were not distinguished by isozymes.

These results demonstrate that combined use of CDA and isozyme analysis is useful for a rapid screening of $P$. vera germplasm and evaluation of variation among male and female germplasm. This isozyme analysis, based on the polymorphism of only three enzymes, allowed identification of $50 \%$ of the female cultivars and all male selections. A similar percentage of identified accessions was obtained with CDA, although with variation in the group of recognized cultivars. Nevertheless, the combination of the two methods enhanced the possibility of uniquely identifying the female cultivars. Identification was difficult or impossible for the compact group of 'Insolia', 'Pignatone', and 'Ghiandalora'. Nevertheless, Dollo (1991) reported a differing isozyme pattern of PGI for 'Insolia' and 'Ghiandalora'; thus, for 'Pignatone', possible synonymy with 'Insolia' or 'Ghiandalora' cannot be excluded. Together, CDA and the rare enzyme patterns in 'Kerman', 'Cerasola', and male selection M9 confirm the greater phylogenetic distance of these genotypes from the other accessions. 'Kerman', the primary American cultivar obtained from an Iranian seedling, belongs to a distinct geographical pool (Joley, 1969); 'Cerasola' is characterized by an extraordinary red pigmentation of the hull, similar to that of 'Red Aleppo'; while M9, locally known as 'Santangilisi', is a putative hybrid between $P$. vera and $P$. terebinthus (Bonifacio, 1942). The more pronounced degree of polymorphism for staminate than for pistillate accessions is probably due to a more intense selection pressure exerted by growers

Table 3. Standardized canonical coefficient (SCC) and correlation coefficient $(r)$ between the first three canonical discriminant functions $\left(\mathrm{CDF}_{1}, \mathrm{CDF}_{2}, \mathrm{CDF}_{3}\right)$ and variables of morphometric characters of the male selections.

\begin{tabular}{|c|c|c|c|c|c|c|}
\hline \multirow[b]{3}{*}{ Character } & \multicolumn{6}{|c|}{ Canonical discriminant function } \\
\hline & \multicolumn{2}{|c|}{$\mathrm{CDF}_{1}$} & \multicolumn{2}{|c|}{$\mathrm{CDF}_{2}$} & \multicolumn{2}{|c|}{$\mathrm{CDF}_{3}$} \\
\hline & SCC & $r$ & SCC & $r$ & SCC & $r$ \\
\hline Leaf rachis length & 0.800 & 0.486 & -0.150 & 0.029 & 0.178 & 0.167 \\
\hline Basal leaflet length & 0.080 & 0.017 & 0.069 & 0.111 & -0.795 & -0.073 \\
\hline Basal leaflet width & -0.439 & -0.294 & 0.828 & 0.311 & -0.044 & 0.286 \\
\hline Central leaflet length & 0.387 & 0.067 & -0.267 & -0.117 & 0.187 & 0.331 \\
\hline Central leaflet width & -0.276 & -0.292 & 0.110 & 0.105 & 0.836 & 0.542 \\
\hline Apical leaflet length & 0.630 & 0.013 & -0.371 & -0.232 & 0.109 & 0.305 \\
\hline Apical leaflet width & -0.769 & -0.271 & -0.275 & -0.113 & -0.024 & 0.418 \\
\hline Inflorescence bud length & -0.346 & 0.066 & -0.047 & 0.322 & -0.979 & -0.263 \\
\hline Inflorescence bud max diameter & 0.087 & 0.302 & 0.331 & 0.579 & -0.013 & 0.043 \\
\hline Inflorescence bud min diameter & 0.184 & 0.256 & 0.476 & 0.586 & -0.080 & 0.031 \\
\hline Inflorescence bud fresh weight & 0.309 & 0.238 & -0.062 & 0.443 & 0.991 & 0.134 \\
\hline Inflorescence bud dry weight & 0.134 & 0.246 & \multirow{2}{*}{\multicolumn{2}{|c|}{20.79}} & -0.038 & 0.046 \\
\hline Variance explained (\%) & \multicolumn{2}{|c|}{58.58} & & & \multicolumn{2}{|c|}{13.31} \\
\hline
\end{tabular}

Table 4. Means of standardized canonical scores of the first three canonical discriminant functions (CDF) for the male selections.

\begin{tabular}{lcrr}
\hline & \multicolumn{3}{c}{ Canonical discriminant function } \\
\cline { 2 - 4 } Male selection & $\mathrm{CDF}_{1}{ }^{\mathrm{z}}$ & $\mathrm{CDF}_{2}{ }^{\mathrm{z}}$ & $\mathrm{CDF}_{3}{ }^{\mathrm{a}}$ \\
\hline M1 & $1.017 \mathrm{c}$ & $-0.513 \mathrm{c}$ & $-1.283 \mathrm{ab}$ \\
M3 & $-0.941 \mathrm{~b}$ & $1.255 \mathrm{~d}$ & $1.094 \mathrm{de}$ \\
M4 & $-0.878 \mathrm{~b}$ & $1.013 \mathrm{~d}$ & $-1.895 \mathrm{a}$ \\
M5 & $-2.311 \mathrm{a}$ & $-2.450 \mathrm{a}$ & $1.459 \mathrm{e}$ \\
M7 & $-0.986 \mathrm{~b}$ & $2.218 \mathrm{e}$ & $0.726 \mathrm{~d}$ \\
M8 & $-2.356 \mathrm{a}$ & $-0.300 \mathrm{c}$ & $-0.189 \mathrm{c}$ \\
M9 & $5.804 \mathrm{~d}$ & $0.190 \mathrm{c}$ & $0.991 \mathrm{de}$ \\
M10 & $1.319 \mathrm{c}$ & $-1.677 \mathrm{~b}$ & $-0.805 \mathrm{bc}$ \\
\hline
\end{tabular}

${ }^{\mathrm{z}}$ Mean separation within each column by Tukey's HSD test $(P \leq 0.01)$.

on the female trees and to the lack of seed propagation that would confirm the statements of many authors that vegetative propagation is the only propagation method used by growers (Bonifacio, 1942; Minà Palumbo, 1882). The existence of a rare isozyme pattern, if substantiated by further research, might suggest the existence of two distinct genetic pools within the pistachio germplasm of Sicily. This hypothesis could be explained by sequential introductions of genetic material, the reddish 'Cerasola' from Syria by the Romans and the later introductions by the Arabs. This sequence would confirm Maggs' (1973) statement that Sicily can be regarded as a late, secondary, center of pistachio genetic diversity.

Further investigation, extended to other genotypes from various countries and other enzyme systems or DNA analysis techniques, not susceptible to environmental influences, would answer this question.

\section{Literature Cited}

Alessandri, S. and E. Casini. 1992. L'uso dell' analisi discriminante multivariata (classificatoria e canonica) nell'elaborazione di dati carpometrici, in applicazioni su castagno e clementine. Prove diprocedure di calcolo avanzate per il trattamento delle informazioni provenienti dall'attività di reperimento di germoplasma. Proc. Congresso su: Germoplasma frutticolo. Alghero, Italy, 2125 Sept. p. 623-628.

Arulsekar, S. and D.E. Parfitt. 1986. Isozyme analysis procedures for stone fruits, almond, grape, walnut, pistachio, and fig. HortScience 21:928933.

Barone, E., T. Caruso, and L. Di Marco. 1985. Il
Table 5. Percentage of correctly predicted group membership of female and male accessions backclassified using the first three canonical discriminant functions.

\begin{tabular}{cc}
\hline \hline Accession & $\begin{array}{c}\text { Cases correctly } \\
\text { classified (\%) }\end{array}$ \\
\hline Female cultivar ${ }^{2}$ & 74 \\
A & 79.6 \\
B & 76 \\
C & 74 \\
D & 70 \\
E & 85.8 \\
F & 63.3 \\
G & 94 \\
H & 96 \\
I & 100 \\
J & \\
Male selection & 80.9 \\
M1 & 70 \\
M3 & 81.3 \\
M4 & 91.1 \\
M5 & 69.4 \\
M7 & 90 \\
M8 & 97.7 \\
M9 & 76.6 \\
M10
\end{tabular}

${ }^{ } \mathrm{A}=$ 'Bianca'; $\mathrm{B}=$ 'Cappuccia'; $\mathrm{C}=$ 'Cerasola'; $\mathrm{D}=$ 'Ghiandalora'; $\mathrm{E}=$ 'Gialla'; $\mathrm{F}=$ 'Insolia'; $\mathrm{G}=$ 'Pignatone'; $\mathrm{H}=$ 'Silvana'; $\mathrm{I}=$ = Tardiva'; $\mathrm{J}=$ 'Kerman'.

pistacchio in Sicilia: Superfici coltivate e aspetti agronomici. L'Informatore Agrario 40:35-42.

Bonifacio, P. 1942. Il pistacchio. Coltivazione, commercio, uso. REDA, Roma.

Bradford, M.M. 1976. A rapid and sensitive method for the quantification of microgram quantities of protein utilizing the principle of protein. Ann. Biochem. 72:248-254.

Caruso, T., L. Di Marco, D. Giovannini, and A. Di 


\section{Breeding, Cultivars, Rootstocks, \& Germplasm Resources}

Pisa. 1986. Caratteristiche carpologiche di 4 cultivar di pistacchio coltivate in Sicilia. Frutticoltura 9-10:63-66.

Caruso, T., L. Di Marco, and A. Raimondo. 1987. Caratteristiche carpometriche di quattro cultivar di pistacchio (Pistacia vera L.) individuate in Sicilia. Agricoltura Ricerca 80:65-68.

Caruso, T., L. Di Marco, R. Lo Bianco, and F. Sottile. 1995. The pistachio germplasm of Sicily: Pomological traits. Proc. IX G.R.E.M.P.A Mtg.-Pistachio. Bronte-Sciacca, 20-21 May 1993.

Cruz-Castillo, J.G., B.R. MacKay, G.S. Lawes, and D.J. Woolley. 1992. Canonical discriminant analysis in kiwifruit rootstock research. Acta Hort. 313:143-148.

Dollo, L. 1991. Aspetti della biologia fiorale di alcune specie del genere Pistacia, caratterizzazione genetica delle stesse e dei loro ibridi. PhD Diss., Università di Catania, Catania, Italy. Gogorcena, Y. and J.M. Ortiz. 1993. Use of multi- variate analysis in the taxonomy of Citrus aurantium L. and relatives. Scientia Hort 53:301-310.

Hillig, K.W. and A.F. Iezzoni. 1988. Multivariate analysis of a sour cherry germplasm collection. J. Amer. Soc. Hort. Sci. 113:928-934.

Joley, L.E. 1969. Pistachio, p. 352-355. In: R.A. Jaynes (ed.). Handbook of Northern American nut trees. Northern Nut Growers Assn., Knoxville, Tenn.

Loukas, M. and C.A. Pontikis. 1979. Pollen isozyme polymorphism in types of Pistacia vera and related species as an aid in taxonomy. J. Hort. Sci. 54:95-102.

Maggs, D.H. 1973. Genetic resources in pistachio. Plant Genet. Res. Nwsltr. 29:7-15.

Minà Palumbo, F. 1882. Monografia botanica ed agraria sulla coltivazione dei pistacchi in Sicilia. Lorsnaider Giovanni Tipografo, Palermo.

Perez-Gonzales, S. 1992. Associations among morphological and phenological characters repre- senting apricot germplasm in Central Mexico. J. Amer. Soc. Hort. Sci. 117:486-490.

Rhodes, A.M., S.E. Malo, C.W. Campbell, and S.G. Carmer. 1971. A numerical taxonomic study of the avocado (Persea americana Mill.). J. Amer. Soc. Hort. Sci. 96:391-395.

Shaw, C.R. and R. Prasad. 1970. Starch gel electrophoresis of enzymes-A compilation of recipes. Biochem. Genet. 4:297-320.

Torres, A.M. 1983. Fruit trees, p. 401-421. In: S.D. Tanksley and T.J. Orton (eds.). Isozymes in plant genetics and breeding. Part B. Elsevier, Amsterdam

Ueda, Y. and Y. Okada. 1994. Discrimination of rose cultivar groups by pollen surface structure. J. Hort. Sci. 69:601-607.

Wilkinson, L. 1990. SYSTAT: The system for statistics. SYSTAT, Evanston, Ill.

Woodroof, J.G. 1967. Pistachio nuts, p. 261-287. In: J.G. Woodroof (ed.). Tree nuts: Production, processing, products. AVI, Westport, Conn. 